\title{
Carreira e contexto institucional no sistema de ensino superior brasileiro'
}

ELIZABETH BALBACHEVSKY"

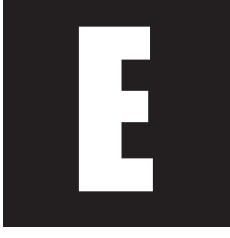

ste trabalho busca estabelecer uma comparação acerca das condições de inserção profissional do professor de ensino superior brasileiro em dois momentos: o início da década de 1990 e o início da década de 2000. O ponto focal desta análise é a interação entre esses profissionais e as oportunidades abertas pela carreira oferecida pela instituição em que ele trabalha. Para realizar este estudo, contamos com dois grandes bancos de dados que permitem a comparação das condições de inserção institucional e trabalho do professor universitário brasileiro ${ }^{1}$ em dois momentos no tempo: 1993 e 2004. As duas pesquisas foram realizadas no NUPES, Núcleo de Pesquisa sobre Ensino Superior da Universidade de São Paulo. A pesquisa de 1993 contou com o apoio da Fundação Carnegie, do Estados Unidos, e foi parte de uma pesquisa mais ampla, realizada em 14 países, que buscava comparar as condições de trabalho da profissão acadêmica em diferentes países (Boyer et al., 1994; Altbach, 1996). A pesquisa de 2003 foi realizada com o apoio da Fundação Ford, e um de seus objetivos explícitos era produzir um

\footnotetext{
* Elizabeth Balbachevsky é professora associada do Departamento de Ciência Política da Universidade de São Paulo e pesquisadora sênior do Núcleo de Pesquisas em Políticas Públicas (NUPPS) da mesma Universidade (área de concentração: políticas de ensino superior). Brasil.

1 Neste estudo, utilizamos a expressão "professor universitário" na acepção corrente do termo, como sinônimo de professor de instituição de ensino superior. Ainda que menos precisa, essa expressão está consagrada na literatura brasileira e também na mídia nacional.
} 
material que permitisse uma análise comparada dos principais indicadores das condições de trabalho desse profissional, passados 10 anos da primeira pesquisa. Por este motivo, o desenho amostral adotado nas duas pesquisa foi idêntico Nos dois casos, temos amostras nacionais, representativas de todo o sistema de ensino superior brasileiro, desde as grande universidades de ensino e pesquisa da região sudeste até as pequenas faculdades isoladas do interior. O questionário aplicado em 2005 preservou a estrutura do questionário que empregamos em 1992, mantendo a comparabilidade de uma porção importante das questões e, ao mesmo tempo, introduziu novos temas e detalhou questões que não nos pareciam ter sido bem cobertos pela pesquisa de 1992.

O resultado deste esforço de pesquisa, portanto, são dois bancos de dados comparáveis, que permitem avaliar a evolução no tempo das condições de emprego e trabalho dos professores do ensino superior brasileiro. O horizonte dessa análise são os últimos dez anos. Boa parte deste período corresponde ao governo de Fernando Henrique Cardoso. Temos, então, um material empírico extremamente relevante. Não apenas por causa de sua comparabilidade, mas porque ele se refere a um período de importantes mudanças na arena regulatória.

\section{O sistema de ensino superior brasileiro: bases da diversidade}

O sistema de ensino superior brasileiro não é apenas grande, mas bastante heterogêneo. No último censo oficial do ensino superior brasileiro, de 2004, encontramos 2.013 instituições, das quais 169 são universidades. Apenas 11\% deste universo é constituído por instituições públicas, sejam federais (4\%), estaduais (4\%) ou municipais (3\%). É bastante conhecida a importância do setor privado no sistema de ensino superior brasileiro: em seu conjunto, essas instituições atendem a 78\% dos quatro milhões de 
estudantes matriculados na graduação. Por sua vez, o setor público responde por 82\% dos 105 mil estudantes matriculados na pós-graduação, seja no mestrado ou no doutorado.

Qualquer análise das condições de trabalho dos professores deste sistema deve levar em consideração a heterogeneidade das condições institucionais de sua inserção na profissão. A classificação oficial, que parte da distinção entre público e privado, não nos parece suficiente do ponto de vista analítico. Ela separa em categorias diferentes instituições que partiIham características semelhantes, como é o caso, por exemplo, da Universidade Federal do Rio de Janeiro e a Universidade de São Paulo, e classifica na mesma categoria instituições tão díspares como a universidade católica do Rio de Janeiro e uma pequena universidade comunitária do interior.

Assim, para a análise dos resultados da pesquisa realizada em 1992, produzimos, na época, uma tipologia de contextos institucionais (Balbachevsky, 2000), que será também utilizada nesta análise. Para a construção dessa tipologia, tomamos como referência duas variáveis centrais para a caracterização das instituições de ensino superior: primeiro, a proporção de doutores no corpo docente, o que é um indicador poderoso da relevância e institucionalização da atividade de pesquisa no interior das instituições, já que o título de doutorado é a exigência mínima para que um pesquisador alcance apoio de fundos públicos de apoio à pesquisa. Em segundo lugar, a proporção de professores da instituição que mantêm um vínculo estável e permanente com a instituição, trabalhando em regime de trabalho de dedicação integral ou exclusiva. Esta outra variável mede a centralidade da instituição para a construção da identidade profissional do professor. Considerando simultaneamente estas duas dimensões, a tipologia produzida pode ser observada no quadro 1, a seguir: 
Quadro 1 - Tipologia de contextos institucionais presentes no sistema de ensino superior brasileiro.

\begin{tabular}{|c|c|c|c|}
\hline \multirow{2}{*}{\begin{tabular}{c} 
Proporção de professores \\
com contrato de tempo \\
integral ou dedicação \\
\cline { 2 - 4 } \begin{tabular}{c} 
exclusiva \\
\cline { 2 - 4 }
\end{tabular}
\end{tabular}} & Baixa & Baixa & Alta \\
\cline { 2 - 4 } & Alta & Contexto de mercado & $?$ \\
\hline
\end{tabular}

Como podemos observar no quadro acima, essa tipologia permite identificar, no sistema de ensino superior brasileiro, pelo menos três contextos institucionais: aqueles nos quais encontramos simultaneamente uma pequena proporção de doutores e de professores com contrato de tempo integral - o que, na nossa tipologia, chamamos de instituições de mercado; aqueles que se caracterizam por apresentar uma pequena proporção de doutores (menos de 50\% de seus professores) em seu quadro acadêmico, mas que oferecem contratos de dedicação integral para um grande número de seus professores (mais de 70\%) - são as instituições que denominamos regionais; e aqueles que apresentam simultaneamente uma alta proporção de doutores (mais de 50\%) em seu quadro docente e também, uma alta proporção de professores em contrato de tempo integral ou dedicação exclusiva (mais de 70\%) - essas são características que singularizam as instituições que poderiam ser classificadas como instituições de pesquisa. Esta denominação acompanha a literatura internacional, que tende a diferenciar instituições nas quais a atividade de pesquisa é central, daquelas em que a pesquisa, mesmo sendo freqüente, é subsumida a outras que são percebidas como prioritárias no ambiente interno da instituição (McCormick, 2000).

Essas denominações não são aleatórias. Elas descrevem a orientação predominante encontrada no ambiente interno dessas instituições. Assim, as instituições que são classificadas na tipologia como sendo de mercado 
incluem a maior parte das universidades e escolas privadas, orientadas basicamente para o provimento de serviços educacionais no nível da graduação. Por isso, essas instituições tendem a dar preferência por compor o seu corpo docente com professores medianamente titulados - valorizando assim o título de mestre - e em contratos de tempo parcial ou em regime de contrato com pagamento por hora-aula. Embora a maioria dessas instituições seja privada, nesta categoria também encontram-se algumas instituições públicas, mais comumente aquelas sob administração municipal e pequenas instituições estaduais.

Já as instituições classificadas como sendo de pesquisa, tendem a valorizar a pós-graduação e, dentro desta, o doutorado. Apesar de seu pequeno número (dezoito ao todo, nos dados oficiais do ano 2.000), essas instituições respondiam por $58 \%$ das matrículas no doutorado no Brasil. A grande concentração de doutores em contratos de tempo integral em seu corpo docente fortalece a orientação acadêmica e tende a valorizar a atividade de pesquisa. As instituições classificadas nesta categoria respondem por uma parte substancial da pesquisa acadêmica feita no Brasil e captam a maior parte dos recursos públicos disponíveis para o fomento desta atividade. Este contexto inclui as grandes universidades públicas brasileiras, algumas federais, outras estaduais e algumas universidades privadas, tais como a Pontifícia Universidade Católica do Rio de Janeiro e a Fundação Getúlio Vargas.

Finalmente as instituições que foram classificadas como regionais são aquelas que combinam simultaneamente uma grande proporção de contratos em tempo integral, com um corpo docente caracterizado por uma titulação média. Nestes casos, a orientação básica da instituição é o ensino de graduação. Nessas instituições, a proporção de doutores é menor, e estes tendem a se concentrar em algumas sub-unidades, que se destacam das demais por sua atividade de pesquisa e pós-graduação, formando o que a literatura brasileira tendeu a classificar como ilhas de exce- 
lência (Oliveira, 1984). Todavia, na maior parte das vezes, essa atividade de pós-graduação permanece restrita ao mestrado, provavelmente porque o número de doutores em condições de liderar a pós-graduação não é suficiente para sustentar um programa de doutorado. A denominação "instituições regionais" decorre dos resultados que obtivemos em outras pesquisas, que reforçaram a percepção de que, entre essas instituições predomina uma forte orientação regional: problemas e questões percebidos como sendo de relevância para a região onde se localiza a instituição tendem a ser valorizados por estes pesquisadores quando elaboram suas agendas de pesquisa, o que não acontece com os pesquisadores ligados às grandes instituições de pesquisa. Neste último ambiente, a agenda do pesquisador se organiza para responder às questões colocadas na comunidade de seus pares, no país e no exterior (Coutinho et al. 2003).

\section{Carreira e titulação nos diferentes contextos institucionais do sistema de ensino superior brasileiro}

Na análise dos resultados da pesquisa realizada em 1993 (Balbachevsky, 2000), a caracterização do ambiente institucional interno de cada um dos tipos de instituições foi feita considerando-se duas dimensões: a estrutura de titulação dos profissionais e a carreira institucional. Do cruzamento destas duas variáveis foi possível distinguir as instituições de ensino superior brasileiras, de acordo com o maior ou menor obstáculo que a falta de titulação (especialmente o doutorado) cria para a ascensão do docente na carreira institucional.

No início dos anos noventa, o título de doutorado era um recurso escasso, até mesmo em instituições situadas em área mais ricas do país. Naquela ocasião, analisando a relação entre estas variáveis - titulação e carreira - era possível identificar três situações bastante distintas: em algumas 
instituições, a falta de titulação criava um obstáculo quase absoluto para a ascensão do profissional na carreira da instituição. Em outras instituições, era possível contornar esse obstáculo mediante a manipulação de outros recursos oferecidos pela própria instituição. ${ }^{2}$ Em outras, ainda, a questão simplesmente não se colocava.

De fato, até o início dos anos noventa - e antes disso - a relação entre titulação e carreira acadêmica no sistema de ensino superior brasileiro estava longe de ser uma relação biunívoca. Ainda que a legislação da reforma de 1968 estipulasse a necessidade de se estabelecer um padrão único entre titulação e carreira, muitas instituições, na prática, criaram "rotas alternativas", que permitiam a ascensão do professor na carreira, dispensando-o do doutorado. ${ }^{3}$

A tabela 2, abaixo, apresenta a relação entre titulação e carreira profissional no sistema de ensino superior brasileiro, nos dois momentos que são analisados neste trabalho: 1992 e 2003. Os dados relativos à posição na carreira foram obtidos a partir da resposta do professor a uma questão fechada, que oferecia as seguintes opções para o professor escolher: "professor titular ou equivalente", "professor adjunto, associado ou equivalente", "professor pleno ou equivalente", "auxiliar de ensino" e "não faz parte da

\footnotetext{
2 Um dos recursos mais comuns era a prática da realização do concurso de livre-docênia em substituição ao doutorado. O concurso de livre-docência é um concurso de ordem institucional e, portanto, não guarda vínculos necessários com a pós-graduação. Até meados da década de noventa, apenas algumas instituições restringiam o acesso a esse título a profissionais com doutorado completo. Na maior parte das instituições públicas e privadas brasileiras, a livre-docência representava, na prática, um caminho alternativo, sob controle da instituição, para admissão e promoção na carreira, que dispensava o doutorado. Sobre o papel da livre docência na estrutura da carreira nas universidades brasileiras, Ver Schwartzman, S. (1992a). Os dados produzidos pela pesquisa de 2003 revelam que essa trajetória caiu em desuso: de fato apenas 2 entrevistados nessa pesquisa declararam a livre-docência como sua titulação mais alta e, ao mesmo tempo, não indicaram ter o doutorado completo.

3 Jacques Schwartzman (1994) até propôs o uso da proporção de professor doutor/Titulares+adjuntos como um bom indicador da maior ou menor frouxidão dos critérios de promoção na carreira em cada instituição.
} 
carreira". Embora diferentes instituições apresentem variações na carreira, estas não parecem ser de tal monta que inviabilizem o uso dessas grandes categorias. Prova disso é o fato de que apenas $11 \%$ dos entrevistados não se sentiram confortáveis com as categorias pré-definidas e optaram por especificar sua posição na carreira em um espaço reservado para esta finalidade.

Tabela 2 - Instituições de Ensino superior no Brasil: relação entre carreira institucional e titulação em 1992 e 2003.

\begin{tabular}{|c|c|c|c|c|c|c|c|}
\hline \multirow{6}{*}{ 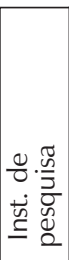 } & \multirow{6}{*}{$\begin{array}{c}\text { Assistente* } \\
\text { Adj/associado } \\
\text { Titular } \\
\text { Total }\end{array}$} & \multicolumn{3}{|c|}{1992} & \multicolumn{3}{|c|}{2003} \\
\hline & & $\begin{array}{c}\text { Mestrado e } \\
\text { menos }\end{array}$ & $\begin{array}{c}\text { Doutorado e } \\
\text { mais }\end{array}$ & Total & $\begin{array}{c}\text { Mestrado e } \\
\text { menos }\end{array}$ & $\begin{array}{c}\text { Doutorado e } \\
\text { mais }\end{array}$ & Total \\
\hline & & 90,7 & 52,7 & 66,7 & 65,4 & 27,8 & 37,5 \\
\hline & & 6,7 & 35,7 & 25,0 & 34,6 & 62,2 & 58,7 \\
\hline & & 2,7 & 11,6 & 8,3 & - & 10,0 & 8,7 \\
\hline & & (75) & (129) & (204) & (26) & (180) & (206) \\
\hline & Assistente* & 53,9 & 6,0 & 41,9 & 65,4 & 24,5 & 46,2 \\
\hline$\dot{\omega}$ & Adj/associado & 41,6 & 77,5 & 50,6 & 27,4 & 63,2 & 44,2 \\
\hline$\subseteq \frac{0}{60}$ & Titular & 4,5 & 16,5 & 7,5 & 7,2 & 12,3 & 9,6 \\
\hline & Total & $(401)$ & (133) & (534) & (179) & (163) & (344) \\
\hline & Assistente* & 56,3 & 15,0 & 52,4 & 53,2 & 27,9 & 47,3 \\
\hline$\frac{\pi}{0}$ & Adj/associado & 15,8 & 5,0 & 14,8 & 20 & 31,7 & 23,2 \\
\hline$\dot{\omega}$ & Titular & 27,9 & 80,0 & 32,9 & 26,1 & 40,4 & 29,5 \\
\hline & Total & (190) & (20) & (210) & $(348)$ & (104) & (452) \\
\hline
\end{tabular}

* Esta categoria inclui os professores que se declararam fora da carreira da instituição e aqueles que se declararam professores-horistas

Fontes: 1992: Carnegie Foundation. International Faculty Survey, Brazil 2003 - Fundação FORD, a profissão acadêmica no Brasil.

Os dados apresentados na tabela acima refletem, em grande medida, os efeitos de importantes processos que marcam o ensino superior brasileiro ao longo dos últimos dez anos. Em primeiro lugar, gostaríamos de chamar a atenção para o aumento da proporção de professores com doutorado em todos os ambientes institucionais que estamos analisando. De fato, entre as instituições que classificamos como sendo de pesquisa, a proporção de doutores passa de 63,2\% em 1992 para 87,4\% em 2005. Entre as institui- 
ções regionais, a proporção de professores com doutorado cresce de 24,9\% para $47,4 \%$. Finalmente, mesmo entre as instituições de mercado, a proporção de doutores, que era insignificante em 1992 (9,5\%), cresce para 23,0\%.

Esse crescimento da proporção de doutores no corpo docente de todas as instituições de ensino superior é, provavelmente, resultado da composição de dois processos simultâneos: em primeiro lugar, o próprio crescimento do sistema de pós-graduação. Se em 1996 formaram-se no Brasil 10.500 mestres e 2.900 doutores, em 2003, o Brasil formou 26.000 mestres e 8.000 doutores. Isso significa que, num intervalo de sete anos, o mestrado no Brasil cresceu 152\%, e o doutorado, 176\%. Um ritmo acelerado que reflete interesse das instituições no prestígio associado à oferta desse nível de educação, às pressões oriundas das instâncias regulatórias do sistema, especialmente com relação às universidades, ${ }^{4}$ o interesse dos próprios acadêmicos e uma política de apoio à pós-graduação, implementada pelo governo federal.

Em segundo lugar, o crescimento da proporção de doutores no corpo docente das instituições de ensino superior no Brasil é resultado da ação das instâncias regulatórias do sistema que, desde o início da década de noventa, passaram a dar grande ênfase à questão da titulação do corpo docente em todos os procedimentos de avaliação. Por fim, estes resultados também são produto, em grande medida, da aprovação da Lei de Diretrizes de Bases, em 1997, a qual estabelece um percentual mínimo de 30\% de professores com titulação mínima de mestrado como um dos requisitos para que uma instituição possa pleitear o seu reconhecimento como Universidade.

4 A Lei de Diretrizes e Bases da Educação de 1997 criou a exigência de que as instituições de ensino superior, para serem acreditadas como universidades devem manter pelo menos três programas de mestrado e um doutorado. 
O crescimento generalizado da proporção de doutores nos quadros docentes das instituições de ensino superior do país, entretanto, teve efeitos contraditórios no que tange à estrutura da carreira profissional dessas instituições. Em primeiro lugar, comparando a distribuição dos "postos" de carreira em cada nível hierárquico para cada contexto institucional, é possível observar importantes mudanças na estrutura de oportunidades abertas aos docentes. Em 1992, nas instituições de pesquisa, a distribuição hierárquica desses "postos" formava o desenho de uma pirâmide: aqui, tínhamos 2,67 postos de assistente para cada associado, e 3,0 postos de associado para cada posto de titular. Já nas instituições regionais, a distribuição de postos assumia o formato de um losango, estreito nas pontas e largo no meio. Naquela época, tínhamos 0,83 assistente para cada associado e 6,75 associados para cada titular. Nas instituições de mercado, a distribuição desses postos assumia um desenho irregular: tínhamos 3,55 assistentes para cada associado e 0,45 associado para cada titular.

As diferenças de "desenho" na distribuição hierárquica dos postos nos contextos institucionais, observadas em 1992 não eram fortuitas. Elas refletiam as oportunidades que se associavam à titulação em cada um desses contextos institucionais. Assim, considerando conjuntamente a proporção de postos de assistente e a proporção de profissionais com titulação de mestrado e menos em cada um desses contextos, pode-se calcular a redução proporcional no erro (RPE) para cada posição de assistente, dada a titulação baixa.

As medidas de Redução-proporcional-no-erro fazem uma comparação da probabilidade de erro sob duas regras de predição (Valle Silva, 1990). Assim, denominando-se a probabilidade de classificação errônea usando-se a regra 1 de $\mathrm{P}(1)$, e essa probabilidade sob a regra 2 de $\mathrm{P}(2)$, uma medida atende ao critério RPE quando esta assume a forma geral $R P E=P(1)-P(2) / P(1)$. 
Adaptando-se este formato geral da regra, temos $\mathrm{P}(1)$ como a probabilidade de erro para assistente na população considerada, que é melhor estimada por $1-\mathrm{N}_{1 .} / \mathrm{N}_{\text {,. }}$ na qual $\mathrm{N}_{1}$ é o total de assistentes na tabela, e $\mathrm{N}$.. corresponde ao total geral de entrevistados na tabela. $\mathrm{P}(2)$, a probabilidade de erro para assistente, conhecida sua pertinência à sub-população de profissionais com titulação baixa, que é mais bem estimada por $1-N_{11} / N_{.1}$, na qual $\mathrm{N}_{11}$ corresponde ao total de assistentes com titulação de mestrado e menos, e $N_{1}$ corresponde ao total de profissionais de baixa titulação. Dessa forma,

$$
\operatorname{RPE}_{\text {(assistente dado baixa titulação) }}=\left(\left(1-\mathrm{N}_{1 . .} / \mathrm{N}_{. .}\right)-\left(1-\mathrm{N}_{11} / \mathrm{N}_{.1}\right) /\left(1-\mathrm{N}_{1 . .} / \mathrm{N}_{. .}\right)\right.
$$

Aplicando essa fórmula geral na tabela II. 1 acima, é possível verificar que, em 1992, entre as instituições que classificamos como sendo de ensino e pesquisa, essa redução era de 0,72 . Isso significa que, neste contexto, saber que o profissional tinha uma titulação baixa (mestrado e menos) reduzia em $72 \%$ o erro em que estávamos incorrendo ao supor que ele também ocupa a posição de assistente na sua instituição. Já no contexto das instituições regionais, este índice era de apenas 0,21 , o que representava uma redução do erro de apenas $21 \%$. Finalmente, nas instituições de mercado, a RPE era de apenas 0,08, o que aponta para a quase independência dessas duas variáveis. Se notarmos que as medidas de RPE variam de 1 a -1 e assumem o valor zero quando as variáveis são completamente independentes, podemos aquilatar com mais precisão o peso que a titulação tinha para a carreira do profissional em cada um dos contextos institucionais.

Quando observamos o comportamento desse índice para os cargos de associado e titular, em conjunto, dada a titulação de doutor, em 1992, os resultados mostram que, no caso das instituições de pesquisa, a redução proporcional no erro para os cargos de associado e titular, dado o doutorado, era de 0,29 (ou 29\%). No caso das instituições do contexto regional e 
do contexto de mercado, a associação entre esses dois atributos era mais forte: 0,81 e 0,73 .

Os resultados observados são compatíveis com a hipótese de que, no início da década de noventa, as instituições classificadas como sendo de pesquisa, de fato tinham poderosos instrumentos internos para reter seus profissionais de baixa titulação nos níveis inferiores da carreira. Por outro lado, no entanto, já naquela época, nessas instituições, a carreira parecia descolar-se da titulação mais alta. A relativa abundância de doutores nas instituições daquele contexto enfraquecia a associação entre a titulação e o acesso aos postos hierarquicamente mais altos.

No caso das instituições regionais, os instrumentos para a retenção dos profissionais de baixa titulação pareciam ser menos eficazes. Por outro lado, entretanto, essas instituições pareciam bastante pródigas com seus doutores. De fato, dada a escassez deste recurso no ambiente interno dessas instituições, o acesso de profissionais com doutorado ao patamar de professor associado era praticamente automático. Assim, pode-se concluir que, no início dos anos noventa, a carreira nas instituições do contexto regional, se, de um lado, reconhecia e premiava a dedicação à carreira acadêmica, expressa na conquista do título de doutor, por outro lado, comportava critérios alternativos que tornavam relativamente freqüente o avanço na carreira independentemente do desempenho acadêmico do profissional. Situação semelhante pode ser observada, ainda que de forma atenuada, no caso das instituições do contexto de mercado.

Quando voltamos nossas atenções para a situação observada em 2003, vemos, em primeiro lugar, alterações importantes no desenho da estrutura da carreira em todos os ambientes institucionais. Nas instituições de pesquisa, a distribuição de postos entre assistente, associado e titular tende pra um losango, com 0,32 postos de assistente para cada posto de associado e 6,72 postos de associado para cada titular. No caso das instituições regio- 
nais, essa distribuição assume a forma de um retângulo na base, no qual temos 1,04 assistentes para cada associado, com um "bico" no extremo, no qual há 4,61 associados para cada titular. Finalmente, no caso das instituições de mercado, temos a figura de um quadrilátero de base mais larga, com 2,04 assistentes para cada associado ao passo que, no topo, encontramos praticamente 1 associado para cada titular.

Quando consideramos as condicionalidades criadas pela titulação acadêmica para o avanço da carreira do profissional na sua instituição, vemos que, passados 10 anos, no caso das instituições de pesquisa, a redução proporcional no erro para assistente, dada baixa titulação decresce, de 0,72 para 0,49 . No caso das universidades regionais, essa redução cresce de 0,21 para 0,36, o mesmo ocorrendo, ainda que de forma modesta, no caso das instituições de mercado, nas quais o RPE-assistente/titulação baixa, cresce de 0,08 para 0,11 .

Este resultado, bastante surpreendente, parece indicar que, no caso das instituições do contexto de pesquisa, as barreiras que retêm os profissionais com titulação menor nos postos mais baixos tenderam a se afrouxar. A explicação para este movimento, entretanto não é difícil: os poucos mestres e especialistas que encontramos nessas instituições ocupando cargos de associado ou adjunto, têm, em média, 53 anos de idade (desvio padrão de 7,8 anos) e estão, em média, há 22,4 anos empregados nessas instituições (desvio padrão de 10,9 anos). São, em geral, significativamente mais velhos do que os doutores ligados a essas instituições, que têm, em média, 48,6 anos de idade (desvio padrão de 9,3 anos). Assim, uma explicação plausível para esta aparente mudança decorre justamente da antigüidade desses profissionais: eles seriam remanescentes de um perfil profissional que já não é mais recrutado por essas instituições.

No contexto regional, os profissionais de baixa titulação, que ocupam postos hierarquicamente mais altos têm um perfil semelhante ao observado 
para as instituições de ensino e pesquisa: eles são em média, mais velhos, com 54,3 anos de idade (desvio padrão de 9,54 anos), em contraposição aos professores de baixa titulação, contratados como assistentes (média de 44,3 e desvio padrão de 8,27 anos). Como, nessas instituições, a associação entre baixa titulação e níveis mais baixos da hierarquia aumentou significativamente na década, pode-se concluir que, aparentemente, nessas instituições, os canais que permitiam o acesso de profissionais com baixa titulação aos postos mais altos da carreira são mais estreitos no presente do que eram no início da década. No caso das instituições ligadas ao contexto de mercado, o quadro de oportunidades que se coloca para os profissionais de baixa titulação permaneceu, em geral, inalterado ao longo dos dez anos que transcorreram entre uma pesquisa e outra.

Considerando agora a situação no outro extremo, isto é, a redução proporcional no erro de supormos que um profissional ocupa a posição de associado ou titular, conhecido que ele é doutor, a variação que se observa neste índice, entre 1992 e 2003 é paradoxal: esse índice diminui significativamente em todos os contextos considerados, indicando um afrouxamento da associação entre alta titulação e o acesso aos postos hierarquicamente superiores da carreira destas instituições. Nas instituições do contexto de ensino e pesquisa, o RPE (associado ou titular/doutor) cai de 0,30 para 0,14 . Nas instituições do contexto regional, esse índice cai de 0,85 para 0,47. Mesmo nas instituições ligadas ao contexto de mercado, esse índice cai de 0,71 para 0,41 Portanto, nos três contextos podemos observar uma diminuição na associação entre alta titulação e alta titulação acadêmica em todos os tipos de instituições do sistema de ensino superior brasileiro. Este resultado, também surpreendente, leva-nos a um questionamento mais detalhado dos determinantes da carreira acadêmica no ensino superior brasileiro, cujos resultados são apresentados a seguir. 


\section{Determinantes da carreira acadêmica no sistema de ensino superior brasileiro}

Duas hipóteses podem dar conta dos resultados descritos na seção anterior. A hipótese mais generosa é a de que nestes 10 anos últimos anos, as exigências da instituição sobre o desempenho acadêmico dos profissionais se tenham acentuado, criando um círculo virtuoso em que a exigência de um desempenho mínimo permanece, mesmo após a obtenção do título de doutor. Isso criaria perfis diferenciados de produtividade acadêmica associados a diferentes níveis da carreira. A outra hipótese é que a carreira oferecida pela instituição esteja, pouco a pouco, perdendo seu efeito discriminador, já que o principal referencial a partir do qual ela foi construída no ensino superior brasileiro - a titulação - tem tendido a se homogeneizar.

Para estabelecer qual dessas duas hipóteses encontra sustentação nos dados coletados pela pesquisa de 2003, procedemos a um exercício de análise multivariada que permite derivar uma função da probabilidade de que um caso seja classificado em determinada categoria da variável dependente $(Y)$, em função de uma combinação linear de $X$ variáveis. Todavia, considerando o fato de que a variável que estamos buscando explicar carreira institucional - é uma variável ordinal, optamos por utilizar o modelo de regressão logítica (logit) ordenada. Assim, rigorosamente, o que esse modelo estima é o logaritmo natural (In) da razão de chances entre acertos e erros para cada categoria (Long, 1997, Borooah, 2002). Para este exercício, os entrevistados foram classificados em quatro patamares de carreira: "fora da carreira", "assistente", "associado e adjunto" e "professor titular".

Assim, o modelo estatístico que será estimado é o seguinte:

$$
\begin{aligned}
& \mathrm{L}_{\mathrm{n}} \mathrm{Y}=\beta_{0}+\beta_{1} X_{1}+\beta_{2} X_{2}+\beta_{3} X_{3}+\beta_{4} X_{4}+\beta_{5} X_{5}+\beta_{6} X_{6}+\beta_{7} X_{7}+\beta_{8} X_{8}+ \\
& \beta_{9} X_{9}+\beta_{10} X_{10}+\beta_{11} X_{11}+\beta_{12} X_{12}+\beta_{13} X_{13}+\beta_{14} X_{14}
\end{aligned}
$$


Onde:

Y corresponde à razão de chances entre as probabilidades para as posições hierarquicamente superiores na escala e aquelas associadas a posições iguais ou hierarquicamente inferiores $\beta_{0}=$ valor cumulativo estimado dos logits $\left(I_{n} Y\right)$ para cada patamar, quando todas as variáveis independentes assumem valor zero.

$\mathrm{E}$,

$X_{1}=$ Antiguidade na instituição, tempo, em anos, do profissional na instituição.

$X_{2}=$ Total de publicações do profissional em livros e revistas especializadas nos três últimos anos.

$X_{3}=$ Total de orientações em mestrado e doutorado concluídas pelo profissional nos últimos três anos.

$X_{4}=$ Total de publicações em livros e revistas especializadas estrangeiras. $X_{5}=$ Titulação máxima, desagregada em: graduação, especialização, mestrado e doutorado

$X_{6}=$ ensino na pós-graduação (mestrado e doutorado). Uma variável dicotômica que mede o envolvimento do profissional na pós-graduação. No questionário, pediu-se para que o profissional estabelecesse quais eram as suas responsabilidades didáticas na instituição.

$X_{7}=$ realiza pesquisa na instituição. Também uma variável dicotômica. Foram classificados como 1, sim, os entrevistados que declararam que estavam realizando pesquisas no âmbito da instituição. Aqueles que declararam que não estavam realizando pesquisa ou que só o faziam fora da instituição, foram classificados como 0, não.

$X_{8}=$ Alcançou financiamento para suas atividades de pesquisa nos últimos três anos. Mais uma vez uma variável dicotômica.

$X_{9}=$ ativismo sindical. Também uma variável dicotômica, na qual a categoria 1 reúne os casos em que o entrevistado declarou participar 
nas atividades da associação docente ou no sindicato de sua instituição, e 0 corresponde aos casos em que o entrevistado declarou não participar (inclusive quando declarou não ter notícias da existência desse tipo de associação em sua instituição).

$X_{10}=$ Centralidade da instituição para o esquema de sustentação financeira do entrevistado, medida pela proporção que o salário pago pela instituição representa nos rendimentos mensais do entrevistado. A literatura latino-americana tende a dar grande ênfase para esta variável nos modelos explicativos que tentam dar conta da qualidade dos vínculos do profissional com sua instituição (Gil-Anton et al., 1994, Gil-Anton, 2003, Grediaga Kuri, 2000 e Grediaga Kuri et al., 2004). Em nosso esquema de análise, essa medida foi tomada como um indicador da centralidade da instituição para a vida profissional do entrevistado.

$X_{11}=$ doutorado. Variável dicotômica que busca verificar o efeito específico do título de doutorado nas chances de ascensão do profissional na carreira institucional.

$X_{12}=$ livre-docência Variável dicotômica que busca verificar o efeito específico do título de livre-docência nas chances de ascensão do profissional na carreira institucional.

$X_{13}=$ especialização. Variável dicotômica que busca verificar o efeito específico do título de especialista (pós-graduação lato-sensu) nas chances de ascenção do profissional na carreira institucional.

$X_{14}=$ mestrado. Variável dicotômica que busca verificar o efeito específico do título de mestrado nas chances de ascensão do profissional na carreira institucional.

Os quadros 3, 4 e 5 que apresentamos abaixo, resumem os resultados obtidos pela regressão logítica ordinal, utilizando-se o fatores discriminados acima, para cada um dos ambientes institucionais. 
Quadro 3 - Parâmetros da correlação ordinal estimados para instituições do contexto de ensino e pesquisa

\begin{tabular}{|c|c|c|c|c|c|c|}
\hline & & coeficiente & Desvio padrão & Wald & $\begin{array}{c}\text { Grau de } \\
\text { liberdade }\end{array}$ & Sig. \\
\hline patamar & [fora da carreira] &,- 328 & 1,600 & 0,42 & 1 &, 838 \\
& [assistente] & 2,483 & 1,601 & 2,406 & 1 &, 121 \\
& [associado/adj] & 6,718 & 1,687 & 15,853 & 1 &, 000 \\
\hline fatores & tempo na inst. &, 062 &, 019 & 10,601 & 1 &, 001 \\
& publicação-total &, 003 &, 020 &, 031 & 1 &, 860 \\
& orientações-tot &,- 011 &, 050 &, 051 & 1 &, 821 \\
& Pub. no exterior &, 058 &, 041 & 2,072 & 1 &, 150 \\
titulação &,- 162 &, 539 &, 090 & 1 &, 764 \\
& ensina na pós &, 153 &, 459 &, 112 & 1 &, 738 \\
faz pesquisa &, 517 &, 547 &, 893 & 1 &, 345 \\
& financiamento p/ &, 219 &, 389 &, 317 & 1 &, 574 \\
pesquisa & & & & & \\
& ativismo &, 049 &, 287 &, 029 & 1 &, 864 \\
& centralidade da &, 014 &, 006 & 5,355 & 1 &, 021 \\
instituição & & & & &, 241 \\
doutorado &, 864 &, 737 & 1,376 & 1 &, 000 \\
livre docência & 2,113 &, 603 & 12,263 & 1 &, 086 \\
especialização &,- 700 &, 408 & 2,949 & 1 & 1 &, 811 \\
mestrado &, 111 &, 465 &, 057 & 1 \\
\end{tabular}

Link function - Logit. Pseudo R² Nagelkerke: 0,270

Fonte - Fundação Ford, Profissão acadêmica no Brasil, 2003.

Os resultados obtidos através deste exercício de regressão são bastante reveladores para a discussão das hipóteses que levantamos acima. No caso das instituições de ensino e pesquisa, uma análise detalhada dos valores de significância alcançados por cada patamar que compõe a variável independente - posição na carreira - mostra que o modelo só permite estimativas com probabilidade de erro menor que $5 \%$ para o último patamar, aquele que separa associados e titulares dos professores alocados em postos hierarquicamente inferiores. Ainda nesse caso, apenas três fatores estão significativamente associados ao acesso a esse patamar: primeiro, a antiguidade do profissional na casa, sendo que aqui a relação obedece ao padrão trivial esperado, no qual, mais tempo na casa redunda em aumentar a razão das chances de o professor ocupar o posto de associado ou titular. 
O segundo fator significativamente associado ao acesso a esse patamar é a centralidade da instituição para os esquemas de sobrevivência do profissional, medida pela importância relativa do salário pago pela instituição com relação à sua renda mensal. Aqui também, quanto mais central é a instituição, mais cresce a razão das chances de o entrevistado alcançar as posições hierarquicamente mais altas na carreira institucional.

Finalmente o terceiro e último fator associado à carreira institucional é a participação do candidato em concursos de livre-docência. A associação aqui é significativa e forte, indicando, como seria de se esperar, que o título de livre-docente é uma condição suficiente (mas não necessária para todas as instituições deste contexto) para a promoção do professor aos últimos degraus da carreira.

Os resultados dessa regressão também surpreendem pelo fato de que os fatores que a literatura tende a tomar como medida de produtividade acadêmica e científica - número de publicações e número de orientações concluídas (Allison \& Stewart, 1974; Clement, 1973, Diamond Jr, 1984, Tien \& Blackburn, 1996, Morey, 2003, entre outros) ou de internacionalização (Schwartzman \& Balbachevsky, 1997; Vessuri, 2003) número de publicações no exterior - mostraram-se não significativos. Da mesma forma, o envolvimento com a pós-graduação, seja medido pelo ensino em cursos de pós-graduação, seja pelo número de orientações concluídas nos últimos três anos, não tem efeitos significativos para estabelecer a posição do professor na carreira da instituição. Também a participação em pesquisa e a capacidade do pesquisador para mobilizar recursos externos para o financiamento de suas atividades de pesquisa tiveram coeficiente de significância muito elevado, portanto, justifica-se a afirmação de que a associação destas dimensões com a mobilidade do professor na carreira profissional tem grande probabilidade de ser aleatória. Por sua vez, o ativismo sindical também se mostrou irrelevante para este resultado. 
Quadro 4 - Parâmetros da correlação ordinal estimados para instituições do contexto regional

\begin{tabular}{|c|c|c|c|c|c|c|}
\hline & & coeficiente & Desvio padrão & Wald & $\begin{array}{c}\text { Grau de } \\
\text { liberdade }\end{array}$ & Sig. \\
\hline patamar & $\begin{array}{c}\text { [fora da carreira] } \\
\text { [assistente] } \\
\text { [associado/adj] }\end{array}$ & $\begin{array}{l}1,206 \\
3,292 \\
6,588\end{array}$ & $\begin{array}{l}, 860 \\
, 874 \\
, 946\end{array}$ & $\begin{array}{c}1,968 \\
14,168 \\
48,514\end{array}$ & $\begin{array}{l}1 \\
1 \\
1\end{array}$ & $\begin{array}{l}, 161 \\
, 000 \\
, 000\end{array}$ \\
\hline fatores & $\begin{array}{c}\text { tempo na inst. } \\
\text { publicação-total } \\
\text { orientações-tot } \\
\text { Pub. no exterior } \\
\text { titulação } \\
\text { ensina na pós } \\
\text { faz pesquisa } \\
\text { financiamento p/ } \\
\text { pesquisa } \\
\text { ativismo } \\
\text { centralidade da } \\
\text { instituição } \\
\text { doutorado } \\
\text { livre docência } \\
\text { especialização } \\
\text { mestrado }\end{array}$ & $\begin{array}{c}, 094 \\
, 004 \\
, 015 \\
, 066 \\
, 234 \\
, 069 \\
-, 244 \\
, 037 \\
\\
, 117 \\
, 010 \\
\\
1,362 \\
23,344 \\
, 190 \\
153\end{array}$ & $\begin{array}{l}, 015 \\
, 016 \\
, 037 \\
, 059 \\
, 297 \\
, 263 \\
, 265 \\
, 253 \\
\\
, 179 \\
, 004 \\
\\
\\
\\
, 412 \\
, 000 \\
, 241 \\
380\end{array}$ & $\begin{array}{c}37,100 \\
, 077 \\
, 169 \\
1,258 \\
, 622 \\
, 068 \\
, 849 \\
, 021 \\
\\
, 429 \\
5,177 \\
10,955 \\
\\
, 619 \\
161\end{array}$ & $\begin{array}{l}1 \\
1 \\
1 \\
1 \\
1 \\
1 \\
1 \\
1 \\
\\
1 \\
1 \\
\\
1 \\
1 \\
1 \\
1 \\
1\end{array}$ & $\begin{array}{l}, 000 \\
, 781 \\
, 681 \\
, 262 \\
430 \\
, 794 \\
, 357 \\
, 884 \\
, 512 \\
, 023 \\
, 001 \\
\\
\\
\\
631\end{array}$ \\
\hline
\end{tabular}

Link function - Logit. Pseudo R2 Nagelkerke: 0,342

Fonte - Fundação Ford, Profissão acadêmica no Brasil, 2003.

No caso das instituições do contexto regional, vemos que o modelo permite estimativas significativas a partir da posição de assistente, já que, a partir deste patamar, temos valores de significância menores que 0,05, o que significa que nossas estimativas têm probabilidade de erro menor do que o limite usualmente aceito em ciências sociais, de 5\%. No caso das instituições do contexto regional, três variáveis independentes se mostraram significativas, isto é, com probabilidade de erro menor do que 5\%: tempo do professor na instituição, centralidade da instituição para a composição da renda mensal do entrevistado e ser ele portador do título de doutor. Para essas três variáveis, os coeficientes estimados pela regressão são positivos, o que significa que incrementos em cada uma dessas variáveis 
independentes aumentam a razão de chances da mobilidade positiva, isto é, em direção a posições mais altas na carreira institucional.

Também para esse contexto, os indicadores que a literatura usualmente associa à produtividade acadêmica e à internacionalização do trabaIho do professor (total de publicações e total de publicações no exterior) se revelaram não significativos. Da mesma forma, o envolvimento com pesquisa e a capacidade para a mobilização de recursos externos para pesquisa tiveram significância alta, e, no entanto, não são relevantes para explicar a posição que o professor ocupa na hierarquia dessas instituições. O mesmo acontece com os indicadores que medem seu envolvimento com a pósgraduação (ensino e total de orientações concluídas) e o ativismo sindical.

Quadro 5 - Parâmetros da correlação ordinal estimados para instituições do contexto de mercado

\begin{tabular}{|c|c|c|c|c|c|c|}
\hline & & coeficiente & Desvio padrão & Wald & $\begin{array}{l}\text { Grau de } \\
\text { liberdade }\end{array}$ & Sig. \\
\hline patamar & $\begin{array}{c}\text { [fora da carreira] } \\
\text { [assistente] } \\
\text { [associado/adj] }\end{array}$ & $\begin{array}{l}, 403 \\
1,342 \\
2,476\end{array}$ & $\begin{array}{l}, 424 \\
, 428 \\
440\end{array}$ & $\begin{array}{c}, 902 \\
9,819 \\
31,652\end{array}$ & $\begin{array}{l}1 \\
1 \\
1\end{array}$ & $\begin{array}{l}, 342 \\
, 002 \\
, 000\end{array}$ \\
\hline $\begin{array}{l}\text { coefi- } \\
\text { ciente }\end{array}$ & $\begin{array}{c}\text { tempo na inst. } \\
\text { publicação-total } \\
\text { orientações-tot } \\
\text { Pub. no exterior } \\
\text { titulação } \\
\text { ensina na pós } \\
\text { faz pesquisa } \\
\text { financiamento p/ } \\
\text { pesquisa } \\
\text { ativismo } \\
\text { centralidade da } \\
\text { instituição } \\
\text { doutorado } \\
\text { livre docência } \\
\text { especialização } \\
\text { mestrado }\end{array}$ & $\begin{array}{c}, 020 \\
-, 020 \\
, 028 \\
, 012 \\
, 431 \\
-, 005 \\
-, 287 \\
, 332 \\
\\
, 100 \\
, 010 \\
\\
, 120 \\
19,904 \\
-, 523 \\
-, 287\end{array}$ & $\begin{array}{l}, 012 \\
, 017 \\
, 035 \\
, 177 \\
, 180 \\
, 223 \\
, 234 \\
, 229 \\
\\
, 142 \\
, 003 \\
\\
\\
, 328 \\
, 000 \\
, 193 \\
272\end{array}$ & $\begin{array}{l}2,751 \\
1,469 \\
, 618 \\
, 005 \\
5,745 \\
, 000 \\
1,505 \\
2,102 \\
\\
, 493 \\
11,227 \\
\\
, 134 \\
7,372 \\
1,119\end{array}$ & $\begin{array}{l}1 \\
1 \\
1 \\
1 \\
1 \\
1 \\
1 \\
1 \\
\\
1 \\
1 \\
1 \\
\\
1 \\
1 \\
1 \\
1\end{array}$ & $\begin{array}{l}, 097 \\
, 226 \\
, 432 \\
945 \\
, 017 \\
, 983 \\
, 220 \\
, 147 \\
\\
483 \\
, 001 \\
\\
\end{array}$ \\
\hline
\end{tabular}

Link function - Logit. Pseudo R² Nagelkerke - 0,131

Fonte - Fundação Ford, Profissão acadêmica no Brasil, 2003. 
Nas instituições do contexto de mercado, o modelo produzido pela regressão ordinal mostra-se eficiente para explicar a mobilidade de professores dentro da carreira, mas não explica a passagem do primeiro patamar para o segundo, isto é, seu ingresso na carreira da instituição. Para esse patamar, o valor estimado não é significativo para uma margem de erro menor ou igual a $5 \%$.

Diferentemente do que se constatou para as instituições dos demais contextos, no caso das instituições orientadas para o mercado, a maior ou menor antiguidade do professor na instituição não afeta significativamente a sua mobilidade. Por outro lado, nesse caso, a titulação do professor mostrou-se significativa, com um valor de significância de 0,017. O valor positivo associado a este coeficiente indica que a titulação mais alta, de fato aumenta a probabilidade de que o professor ocupe posições mais altas na hierarquia da carreira institucional. Porém, tomado isoladamente, o título de especialização está significativa, mas negativamente associado à carreira institucional. Isto é, o título de especialização diminui a probabilidade de que o professor ocupe uma posição alta na hierarquia da instituição, mantidas as outras variáveis constantes. Por outro lado, também a centralidade da instituição para a composição da renda mensal do professor apresentou um coeficiente significativo e positivo. Também aqui, quanto mais importantes são os recursos provenientes de seu trabalho na instituição para a composição da renda do professor, maior a probabilidade de que ele ocupe uma posição alta na hierarquia dessa instituição.

Da mesma forma, para os professores que trabalham em instituições ligadas ao contexto de mercado, sua produtividade acadêmica, medida pelo número de publicações nos últimos três anos; o grau de internacionalização de seu trabalho, aqui medido pelo número de publicações no exterior; seu envolvimento com a pós-graduação e com a pesquisa não são fatores significativamente associados à ascensão na carreira institucional. Igualmente, o 
ativismo sindical é pouco relevante para a posição do professor dentro de sua instituição.

Assim, os resultados obtidos com o exercício de regressão para os diferentes contextos institucionais refutam a hipótese de que, com o aumento da proporção de doutores, as instituições de ensino superior brasileiras tenham criado parâmetros mais exigentes para a promoção na carreira. Em todos os contextos, as chances de que um professor ocupe posições mais altas na hierarquia institucional não é afetada pelo seu maior ou menor desempenho em indicadores que a literatura usualmente associa à produtividade acadêmica e à internacionalização do trabalho acadêmico. Ao contrário, esses resultados são congruentes com a segunda hipótese, a saber, de que a carreira acadêmica, em todas as instituições de ensino superior brasileiras, esteja, pouco a pouco, perdendo sua capacidade para discriminar e recompensar os diferenciais de desempenho de seus profissionais. Parece-nos que, em grande medida, essa situação decorre do fato de que o principal referencial a partir da qual ela foi construída - a titulação - tem tendido a se homogeneizar nos últimos anos, como decorrência das políticas adotadas pelas instâncias regulatórias do sistema, como vimos acima. Por este motivo, também, no setor onde a presença de professores com doutorado ainda é relativamente escassa - o contexto de mercado -, a titulação ainda preserva um potencial de diferenciação nas chances relativas de promoção para seus professores.

Isso não significa, naturalmente, que não haja diferenças expressivas nos indicadores de produtividade e internacionalização, mas, sim, que essas diferenças não encontram expressão na estrutura interna da carreira das instituições. De fato, uma comparação da média associada a cada um desses indicadores, para cada contexto institucional, tal como é apresentada na tabela 6 abaixo, mostra que os contextos institucionais são bastante diferentes, em relação a essas dimensões: 
Quadro 6 - Indicadores de produtividade acadêmica e contexto institucional

\begin{tabular}{|c|c|c|c|}
\hline Contexto institucional & & $\begin{array}{l}\text { Total de livros, artigos e } \\
\text { trabalhos apresentados } \\
\text { em congressos }\end{array}$ & $\begin{array}{c}\text { Publicações no } \\
\text { exterior }\end{array}$ \\
\hline Ensino e pesquisa & $\begin{array}{l}\text { Média } \\
\text { Desvio } \\
\text { Padrão }\end{array}$ & $\begin{array}{c}12,0233 \\
11,04883\end{array}$ & $\begin{array}{r}3,2516 \\
6,51089\end{array}$ \\
\hline Regional & $\begin{array}{l}\text { Média } \\
\text { Desvio } \\
\text { Padrão }\end{array}$ & $\begin{array}{c}8,0872 \\
8,67966\end{array}$ & $\begin{array}{c}, 8516 \\
2,19713\end{array}$ \\
\hline Mercado & $\begin{array}{l}\text { Média } \\
\text { Desvio } \\
\text { Padrão }\end{array}$ & $\begin{array}{c}4,4284 \\
6,34092\end{array}$ & $\begin{array}{l}, 1639 \\
, 56487\end{array}$ \\
\hline Total & $\begin{array}{l}\text { Média } \\
\text { Desvio } \\
\text { Padrão }\end{array}$ & $\begin{array}{c}7,1930 \\
8,76011\end{array}$ & $\begin{array}{r}1,0386 \\
3,44975\end{array}$ \\
\hline
\end{tabular}

Análise de variância para cada um desses indicadores apresentou os seguintes resultados - Total de Publicação: $\mathrm{f}=60,58$, significativo para $\alpha=0,000 . \mathrm{Eta}^{2}=0,109$

Total de publicação no exterior $=65,31$ significativo para $\alpha=0,000 \mathrm{Eta}^{2}=0,115$

Fonte - Fundação Ford, Profissão acadêmica no Brasil, 2003.

Como se vê, os professores ligados ao contexto de ensino e pesquisa são, em média, significativamente mais produtivos e internacionalizados do que seus colegas que trabalham em instituições do contexto regional. Em média, enquanto os primeiros publicaram 12 trabalhos nos últimos três anos, dos quais, três no exterior, os segundos publicaram 8 trabalhos no mesmo período, dos quais apenas 1 no exterior. Já os professores ligados ao contexto de mercado publicaram, em média, apenas quatro artigos nos últimos três anos e, entre esses professores, apenas um em cada 10 trabaIhos foi publicado no exterior. A análise de variância dessas medidas entre os professores dos três contextos mostra não apenas que essas diferenças são significativas para um erro menor que $0,1 \%$, mas que o contexto 
institucional é uma variável poderosa para explicar a variância associada a cada uma dessas medidas: ela explica $10 \%$ da variância observada para a medida do total de publicações e 11,5\% da variância observada para o total de publicações feitas no exterior.

Mas, se as regras que regulam a ascensão do professor na carreira, dentro de sua instituição, são frágeis para captar diferenças no perfil acadêmico, elas não são indiferentes ao envolvimento do profissional com sua instituição. De fato, as duas medidas que podem ser tomadas como indicadores dessa dimensão, no modelo discutido acima, estão significativamente associadas às oportunidades de ascensão na carreira: a antiguidade do professor na instituição e a centralidade da instituição para a sua vida profissional. Podemos então dizer que a carreira acadêmica no Brasil, de fato incentiva e premia, a dedicação integral do professor à sua instituição. Este resultado contrasta com a realidade de sistemas de ensino superior de outros países da América Latina, onde essa dimensão é bem menos relevante para determinar a estrutura de oportunidades que a carreira acadêmica abre para o professor (Gil-Antón, 2003; Marquis, 2003; Grediara-Kuri et al. 2004 e Garcia-Fanelli, 2004).

\section{Conclusões}

Este trabalho apresentou as bases para uma classificação tipológica rigorosa das instituições que compõem o sistema de ensino superior brasileiro. Para além das classificações usuais, que tomam como referência a propriedade da instituição ou sua cobertura disciplinar, nossa proposta foi a de produzir uma tipologia que tivesse como ponto de partida as características que marcam a dinâmica interna dessas instituições. As bases para essa tipologia já haviam sido desenvolvidas em minha tese de doutorado. Assim, tendo como ponto de partida o estudo feito em 1995, propomos uma 
classificação das instituições de ensino superior que tenha como referência duas variáveis que se mostraram definidoras de várias características relevantes da instituição: a proporção de doutores dentro do corpo docente da instituição e a proporção de professores contratados em tempo integral.

A nosso ver, essas duas características são relevantes porque indicam, de um lado, o potencial de produção de conhecimento da instituição, que guarda uma relação direta com a proporção de professores que tiveram uma formação completa como pesquisadores. Por outro lado, elas medem, ainda que indiretamente, o grau de autonomia da corporação acadêmica no interior da instituição. Assim, a classificação produzida por essa tipologia permite ir além de uma discussão que opere na simples contraposição entre público e privado no ensino superior, incorporando nuances da vida acadêmica, que fazem da Pontifícia Universidade Católica do Rio de Janeiro, por exemplo, uma instituição muito mais próxima das grandes universidades públicas brasileiras do que de seus "pares" no modelo de classificação oficial.

O passo seguinte na análise foi realizar um exercício comparando os resultados da pesquisa de 1992 com aqueles obtidos pela pesquisa de 2003. Nessa análise, na comparação, esteve focada na evolução da relação entre titulação e carreira institucional, entre 1992 e 2003, nos diferentes contextos institucionais. Os resultados obtidos foram surpreendentes porque apontavam para uma desorganização crescente da estrutura da carreira nas instituições de ensino superior brasileiras e um enfraquecimento na associação entre titulação e carreira. Uma vez que eles se combinam com uma participação crescente de profissionais titulados (doutores) no corpo docente dessas instituições, duas hipóteses se apresentam: a primeira é a de que, nestes 10 anos últimos anos, as pressões da instituição sobre o desempenho acadêmico dos profissionais - que antes se concentravam na obtenção da titulação - tenham-se acentuado, criando um círculo virtuoso em que a 
exigência de um desempenho mínimo permanece, mesmo após o doutorado. Isso criaria perfis diferenciados de produtividade acadêmica, associados a diferentes níveis da carreira. A outra hipótese é que as carreiras oferecidas pelas instituições de ensino superior brasileiras estejam, pouco a pouco, perdendo seu efeito discriminador do desempenho, já que o principal referencial a partir do qual ela foi construída - a titulação - tendeu na última década a se homogeneizar.

Para estabelecer qual dessas duas hipóteses encontra sustentação nos dados coletados pela pesquisa de 2003, procedemos a um exercício de análise multivariada, que permite derivar uma função da probabilidade de que um caso seja classificado em determinada categoria da variável dependente $(Y)$, em função de uma combinação linear de $X$ variáveis. Entre as variáveis escolhidas para compor o modelo, utilizamos indicadores de produtividade, de antiguidade na instituição, de titulação e de centralidade da instituição para a atividade profissional do entrevistado. Pudemos então constatar que, de fato, os dados da pesquisa refutam a hipótese de que a carreira acadêmica no Brasil tenha-se tornado mais exigente nos últimos dez anos. Nossa análise mostra que, em todos os contextos institucionais, a carreira institucional não guarda relação significativa com os indicadores relativos à produção acadêmica e à internacionalização do trabalho do professor. Mas ela é, ao contrário, bastante afetada pelos indicadores que medem a centralidade da instituição para a vida profissional do professor: quanto maior a antiguidade do professor na casa e quanto maior a relevância da instituição para a composição da renda do entrevistado, maiores são as chances de que ele ocupe uma posição alta na carreira da instituição. Tampouco se pode descartar a hipótese de uma direção causal inversa, isto é, de que a instituição tenda a premiar com postos mais elevados aqueles profissionais que buscam uma vinculação mais forte com as instituições em que eles concentram parte mais significativa de seu salário e nas quais têm maior antiguidade. 
Portanto, os resultados de nossos dados corroboram a hipótese de que a carreira oferecida pelas instituições de ensino superior brasileiras esteja, pouco a pouco, perdendo sua capacidade de discriminar e recompensar o desempenho acadêmico, já que o principal referencial a partir da qual ela foi construída - a titulação - tendeu, na última década, a se homogeneizar.

A análise que empreendemos aqui contribui para um debate que apenas agora começa a tomar forma no interior do sistema de ensino superior brasileiro: a base sobre a qual se estrutura a carreira docente, e, no caso das instituições públicas, o nível de autonomia dessas instituições para reconhecer e estimular diferentes tipos de atividades que o professor cumpre no seu dia-a-dia.

A carreira institucional presente na maioria das instituições de ensino superior no Brasil tem uma estrutura básica que data da reforma de 1968. Naquela época, o valor acadêmico mais escasso no cenário da educação superior no País era a titulação pós-graduada, seja de mestrado ou de doutorado. Não por outro motivo, a carreira da maior parte das instituições brasileiras incorporou essa hierarquia de titulação como a principal referência para se estruturar. Entretanto o cenário que se descortina para o ensino superior no Brasil, na primeira década do século XXI, mudou drasticamente. O crescimento da pós-graduação tornou a titulação pós-graduada um recurso bastante comum. As novas demandas colocadas pela sociedade e pelo governo para as instituições de ensino superior criam um cenário mais complexo, onde os parâmetros para a avaliação dessas instituições são mais heterogêneos e, ao mesmo tempo, mais precisos. Nesse novo cenário, a carreira de nossas universidades permaneceu praticamente a mesma, criando óbvias disfuncionalidades. Para o professor, esse cenário empobrece artificialmente as suas perspectivas de carreira dentro da instituição, gerando um descompasso entre as recompensas que ele alcança junto aos seus 
pares, com o seu trabalho de pesquisa, ensino e extensão, e o reconhecimento formal deste esforço no interior da instituição. Para as instituições de ensino superior, a manutenção deste modelo arcaico de carreira priva-as de um importante instrumento de política institucional.

\section{Referências}

ALLISON, P.D. \& STEWART, J.A. Productivity differences among scientists: evidence for accumulative advantage. American Sociological Review, 39, 596-606, 1974.

ALTBACH, P. G. (ed.) The International Academic Profession: portraits of fourteen countries. Princeton: The Carnegie Foundation, 1996.

BALBACHEVSKY, E. A profissão acadêmica no Brasil: as múltiplas facetas do nosso sistema de ensino superior. Brasília, FUNADESP, 2000.

BOROOAH, V.K. Logit and Probit. Thousand Oaks: Sage Publication, 2002.

BOYER, E. L.; ALTBACH, P. G. e WHITELAW, M. J. The Academic Profession: an international perspective. Princeton: The Carnegie Foundation, 1994.

CLEMENT, F. Early career determinants of research productivity. In: American Journal of Sociology, no79, 409-419, 1973.

COUTINHO, M.; BALBACHEVSKY, E; HOLZHACKER; PATRÃO D. C; VÊNCIO, R. N. Z.; SILVA, R. L. M.; M.LUCATELLI, Reis, L. F \& MARIN, M. A. Intellectual Property Rights and Public Research in Biotechnology: The Scientists Opinion. Scientometrics. 58-3 Pp. 641-656, 2003.

DIAMOND JR. A. M. An economic model of the life-cycle research productivity of scientists. In: Scientometrics, 6 (3) 189-196, 1984.

GARCÍA-FANELLI, A.M.. Academic Employment Structures in Higher Education: The Argentine Case and the Academic Profession in Latin America. In: Sectoral Activities Programme, Geneva, International Labour Office, 2004.

GIL-ANTON, M.; KURI, R. G.; FRANCO, L. P.; LÓPEZ, N. R. e ALVARADO, M. A. C. Los rasgos de la diversidad: un estudio sobre los académico mexicanos. Azcapotzalco: Universidade Autónoma Metropolitana, 1994. 
GIL-ANTON, M. "Big city love: the academic workplace in Mexico". In ALTBACH, $\mathrm{P}$. (org.) The decline of the guru: the academic profession in developing and middle-income countries. New York: Palgrave Macmillan. p. 23-50, 2003.

GREDIAGA-KURI, R.. Professión académica, disciplinas y organizaciones. Cidade do Mexico: Anuies, 2000.

GREDIAGA-KURI, R.; JIMÉNEZ, J. R. R. e GONZÁLEZ, L. E. P. Políticas Públicas y cambios en la professón académica en Méjico en la última década. Azcapotzalco: Universidade Autonoma Metropolitana, Anuies, 2004.

LONG, J. S. Regression models for categorical and limited dependent variables. Thousand Oaks: Sage Publication, 1997.

MARQUIS, C. "Universities and professors in Argentina: changes and challenges". In ALTBACH, P. (org.) The decline of the guru: the academic profession in developing and middle-income countries. New York: Palgrave Macmillan. P. 5174, 2003.

MCCORMICK, A. C. The Carnegie Classification of Institutions of Higher Education. Princeton: The Carnegie Foundation, 2000.

MOREY, A. I. "Major trends impacting faculty roles and rewards: an international perspective". In: EGGINS, H. (Ed.). Globalization and reform in higher education. Londres: Society for Research into Higher Education and Open University Press, Pp. 68-84, 2003.

OLIVEIRA, J. B. A. Ilhas de competência: carreiras científicas no Brasil. São Paulo: Ed. Brasiliense, 1984.

SCHWARTZMAN, J. "Um sistema de indicadores para as universidades brasileiras". Documentos de trabalho NUPES 5/94, 1994.

SCHWARTZMAN, S. e BALBACHEVSKY, E. "The academic profession in Brazil". In Altbach, Philip. G. (ed.). The international academic profession: portraits of fourteen countries. Princeton: The Carnegie Foundation for the Advancement of Teaching. Pp. 231-278, 1997.

TIEN, F. F. \& BLACKBURN, R. T. "Faculty rank system, research motivation and faculty research productivity: measure refinement and theory testing" In: Journal of Higher Education, vol. 67, n. 1. Pp. 3-22. 
Sociologias, Porto Alegre, ano 9, no 17, jan./jun. 2007, p. 158-188

VALLE e SILVA, N. Introdução à análise de dados qualitativos. Rio de Janeiro: Vértice Universitária, 1990.

VESSURI, H. "Science and Higher Education in the process of internationalization: Elements for a conceptual framework for Latin America". Unesco: Forum Regional Scientific Committee for Latin America and Caribbean, Occasional Paper No. 3, 2003.

\section{Resumo}

Este trabalho faz um estudo da evolução da relação entre titulação e carreira institucional, entre 1992 e 2003, nas instituições de ensino superior brasileiras, usando para isso dados coletados em dois surveys representativos da profissão acadêmica no Brasil. Os resultados obtidos foram surpreendentes porque apontam para uma desorganização crescente da estrutura da carreira nas instituições de ensino superior brasileiras e um enfraquecimento na associação entre titulação e carreira. $\mathrm{O}$ estudo apresenta ainda um exercício de análise multivariada para verificar quais dimensões são relevantes para explicar a ascensão do professor a diferentes degraus da carreira. O resultado dessa análise corrobora a hipótese de que a carreira oferecida pelas instituições de ensino superior brasileiras esteja, pouco a pouco, perdendo sua capacidade de discriminar e recompensar o desempenho acadêmico, já que o principal referencial a partir da qual ela foi construída - a titulação - tendeu, na última década, a se homogeneizar.

Palavras chaves: Brasil, ensino superior, profissão acadêmica, produtividade acadêmica, carreira acadêmica.

Recebido: 11/12/06

Aceite final: 15/02/07 


\section{Career and institutional context in Brazil's higher education system}

\section{Elizabeth Balbachevsky}

This work studies the development of the relationship between academic title and institutional career between 1992 and 2003, in Brazil's higher education institutions, based on data collected in two surveys that are representative of the academic profession in Brazil. Results obtained were surprising because they point to an increasing disorganization of career structure in Brazilian higher education institutions and a decrease in the association between title and career. The study also presents a multivariate analysis exercise to see which dimensions are relevant to explain the rise of professors to distinct career levels. Results corroborate the hypothesis that the career offered by Brazilian higher education institutions is gradually losing its ability to discriminate and reward academic performance, since the main reference on which it has been built - academic title - tended to homogenize in the last decade.

Key words: Brazil, Higher education, Academic profession, Academic career. 